\title{
Single breath transfer factor measured concurrently by two methods in asthmatic and normal subjects
}

\author{
S. P. H A Y D U \\ Department of Chest Medicine, The London Hospital, London E1
}

\begin{abstract}
Haydu, S. P. (1974). Thorax, 29, 232-236. Single breath transfer factor measured concurrently by two methods in asthmatic and normal subjects. There have been conflicting reports that the single breath transfer factor for carbon monoxide in asthma may be normal, high or low. To resolve this point the single breath transfer factor was measured in comparable groups of asthmatic and normal subjects. Two methods of calculating the alveolar volume were used, employing multiple breath helium dilution (giving $T_{L}$ ) and single breath helium dilution (giving $T_{L}{ }^{\prime}$ ).

A higher value was found for $T_{L}$ than for $T_{L}{ }^{\prime}$ in the asthmatic subjects but a lower value for $T_{L}$ than $T_{L^{\prime}}$ in the normal subjects. These differences were significant. The largest differences were found in the asthmatic subjects with a large residual volume. There was no significant difference between the asthmatic and normal subjects in the value of $T_{L}$ and $T_{L}{ }^{\prime}$. As the reports of a raised transfer factor were from workers who used $T_{L}$, and this was not confirmed by those who used $\mathbf{T}_{\mathbf{L}}{ }^{\prime}$, it is concluded that this apparent difference between normal and asthmatic subjects can be explained in some cases by the difference in the methods used.
\end{abstract}

The single breath transfer factor for carbon monoxide has been measured in patients with chronic airways obstruction by many workers. It has been found to be low in emphysema (Fletcher, Hugh-Jones, McNicol, and Pride, 1963) and may be low or normal in chronic bronchitis (Palmer and Diament, 1969a).

There have been conflicting reports in asthma. However, most authors agree that the transfer factor is normal (Meisner and Hugh-Jones, 1968; Cotes et al., 1970). Palmer and Diament (1969b) reported that, although the transfer factor was usually normal in asthma, it was sometimes reduced in patients with a relatively severe degree of airway obstruction. On the other hand, Ogilvie (1968) described an increased transfer factor in some asthmatics.

The results may vary because of the different ways of calculating the transfer factor. Ogilvie (1968) and Meisner and Hugh-Jones (1968) used the method described by Ogilvie, Forster, Blakemore, and Morton (1957), in which the alveolar volume is taken as the sum of the inspired volume of the test breath and the residual volume found by multiple breath helium dilution in a separate determination $\left(V_{A}\right)$. Palmer and Diament (1969b) calculated the transfer factor using alveolar volume derived from the helium dilution of the test breath $\left(\mathrm{V}_{\mathrm{A}}{ }^{\prime}\right)$.

\section{MATERIAL AND METHODS}

Thirty asthmatic subjects (20 male and 10 female) were studied between exacerbations of asthma. They were studied in this stage because the test for transfer factor is difficult to perform in the presence of severe dyspnoea and $\bar{\partial}$ the readings might be less reproducible. All the asthmatic subjects were under the care of the hospital as either in- or out-patients. They had shown variations in forced expira- 3 tory volume in one second $\left(\mathrm{FEV}_{1}\right)$ of at least $20 \%$ (usually over $30 \%$ ) spontaneously or in response to therapy. The majority had positive skin tests and a raised eosinophil

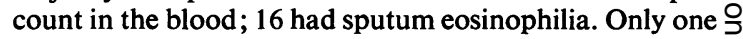
was a smoker and none had large amounts of sputum. All $D$ had normal chest radiographs and a normal haemoglobin 을. concentration. None had evidence of aspergillosis or $\overline{\mathrm{N}}$ allergic alveolitis. The 30 normal subjects had the same sex $\sigma$ distribution. The height and age did not differ significantly $N$ from those of the asthmatic subjects (Table I). Three of the $N$ normal subjects were light cigarette smokers, the rest were $\omega$ non-smokers.

The following procedure was carried out in all cases. Noo bronchodilators were taken before the tests on that day. $\frac{\bar{D}}{\Phi}$ Other drug therapy was not changed. Measurements of $\stackrel{\infty}{+}$ the vital capacity and $\mathrm{FEV}_{1}$ were made using a dry wedge $\tau$ spirometer (Vitalograph). The results were corrected to $\bar{O}$ BTPS. The single breath transfer factor was measured in $\overrightarrow{\mathbb{D}}$ duplicate using the method described by Cotes (1968) with $\frac{\rho}{\mathbb{D}}$ a Resparameter Mark 4 (P. K. Morgan). The mean value $\varrho$ was calculated. The total lung capacity and its subdivisions were measured by the closed-circuit helium dilution $\delta$ 
T A B L E I

RESULTS OF NORMAL SUBJECTS

\begin{tabular}{|c|c|c|c|c|c|c|c|c|c|c|c|c|}
\hline & \multirow{2}{*}{$\begin{array}{c}\text { Height } \\
\text { (cm) }\end{array}$} & \multirow{2}{*}{$\begin{array}{l}\text { Age } \\
(y r)\end{array}$} & \multicolumn{2}{|c|}{ FEV $_{1}$} & \multicolumn{2}{|c|}{$T_{L}$} & \multicolumn{2}{|c|}{$T_{L^{\prime}}$} & \multicolumn{2}{|c|}{ TLC } & \multicolumn{2}{|c|}{$\mathbf{R V}$} \\
\hline & & & Litres & $\begin{array}{c}\% \\
\text { Pred. }\end{array}$ & $\underset{\mathrm{mmHg}}{\mathrm{ml} / \mathrm{min} /}$ & $\begin{array}{c}\% \\
\text { Pred. }\end{array}$ & $\underset{\mathbf{m m H}}{\mathrm{ml} / \mathrm{min} !}$ & $\begin{array}{c}\% \\
\text { Pred. }\end{array}$ & Litres & $\begin{array}{c}\% \\
\text { Pred. }\end{array}$ & Litres & $\begin{array}{c}\% \\
\text { Pred. }\end{array}$ \\
\hline $\begin{array}{l}\text { Mean } \\
\text { Range } \\
\text { SEM }\end{array}$ & $\begin{array}{c}175 \cdot 0 \\
152-187 \\
1 \cdot 59^{1}\end{array}$ & $\begin{array}{c}34 \cdot 2 \\
13-66 \\
2 \cdot 208\end{array}$ & $\begin{array}{c}4 \cdot 01 \\
2 \cdot 44-6 \cdot 1 \\
0 \cdot 186\end{array}$ & $\begin{array}{c}109 \cdot 6 \\
81-145 \\
2 \cdot 78\end{array}$ & $\begin{array}{c}28 \cdot 6 \\
19-39 \cdot 2 \\
1 \cdot 15\end{array}$ & $\begin{array}{c}92 \cdot 7 \\
72-120 \\
2 \cdot 72\end{array}$ & $\begin{array}{c}30 \cdot 1 \\
18 \cdot 8-48 \cdot 5 \\
1 \cdot 42\end{array}$ & $\begin{array}{c}97 \cdot 1 \\
74-131 \\
3 \cdot 04\end{array}$ & $\begin{array}{c}6.29 \\
3.87-9 \cdot 65 \\
0.263\end{array}$ & $\begin{array}{c}100 \cdot 4 \\
77-138 \\
2 \cdot 54\end{array}$ & $\begin{array}{c}1 \cdot 53 \\
0.76-3 \cdot 34 \\
0 \cdot 10\end{array}$ & $\begin{array}{c}84 \cdot 6 \\
55-142 \\
4 \cdot 79\end{array}$ \\
\hline
\end{tabular}

1The standard error of the mean for height for the males and females can be expressed separately because of the large difference in the mean values. SEM: males $1 \cdot 410$, females $1 \cdot 670$.

technique using the Godard Pulmotest and a katharometer for the measurement of helium concentration. These results were corrected to BTPS.

The single breath transfer factor was calculated in two ways: (1) using alveolar volume derived from the addition of the residual volume obtained by the closed-circuit technique to the inspired volume of the test breath. This will be referred to as $V_{A}$ and the resulting transfer factor as $T_{L} ;(2)$ using alveolar volume derived from the dilution of the helium in the alveolar sample. As described by McGrath and Thomson (1959) this is referred to as $V_{A^{\prime}}$ and the transfer factor as $T_{L}{ }^{\prime}$. The studies were carried out concurrently in the asthmatic and normal groups and the tests were all performed by the author, thereby standardizing procedure.

\section{RESULTS}

The mean, range, and standard error of the mean of the results in the normal and asthmatic subjects are shown in Tables I and II. The results of the height, age, $F_{E V}, T_{L}, T_{L}^{\prime}$, total lung capacity (TLC), and residual volume (RV) are given, and where appropriate they are also expressed as per cent of the predicted value. The predicted values were obtained from Cotes (1968).

The following showed significant differences between the mean values:

1. FEV 1 was significantly less in the asthmatic group $(\mathrm{P}<0.01 ; t 6.1119 ;$ df 58$)$

2. Residual volume was significantly greater in the asthmatic group $(\mathrm{P}<0.01 ; t 4.50 ; \mathrm{df} 58)$

3. $T_{L}$ was significantly higher than $T_{L}{ }^{\prime}$ within the asthmatic group $(\mathrm{P}<0.01 ; t 3.5291 ;$ df 58$)$
4. $T_{L}{ }^{\prime}$ was significantly higher than $T_{L}$ within the normal group $(\mathrm{P}<0.01 ; t 2.8771 ;$ df 58$)$.

There was no significant difference between the mean values of $T_{L}$ in the asthmatic group and the normal group. The same applied when $T_{L^{\prime}}{ }^{\prime}$ was compared in the two groups. The results, comparing $T_{L}$ and $T_{L}{ }^{\prime}$, are shown diagramatically (Fig. 1). The mean value for the transfer factor was close to the predicted mean value by both methods in the normal and asthmatic subjects. When both groups were considered together there was no significant difference between the $T_{L}$ and $T_{\mathbf{L}}{ }^{\prime}$. Table III shows the numbers of asthmatic and

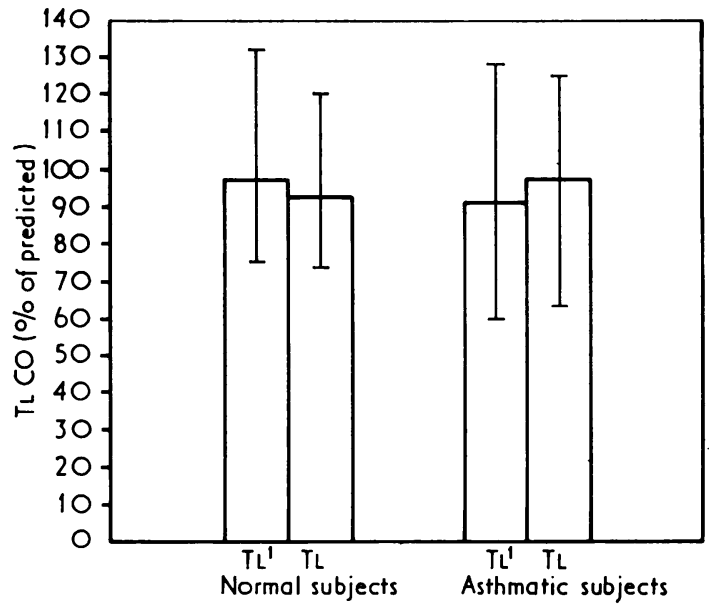

FIG. 1. Mean and range of $\mathrm{T}_{\mathrm{L}}$ and $\mathrm{T}_{\mathrm{L}}{ }^{\prime}$ in normal and asthmatic subjects.

T A B L E I I

RESULTS OF ASTHMATIC SUBJECTS

\begin{tabular}{|c|c|c|c|c|c|c|c|c|c|c|c|c|}
\hline & \multirow{2}{*}{$\underset{\text { (cm) }}{\text { Height }}$} & \multirow{2}{*}{$\begin{array}{l}\text { Age } \\
(\mathbf{y r})\end{array}$} & \multicolumn{2}{|c|}{ FEV $_{1}$} & \multicolumn{2}{|c|}{$\mathrm{TL}$} & \multicolumn{2}{|c|}{$T_{L^{\prime}}$} & \multicolumn{2}{|c|}{ TLC } & \multicolumn{2}{|c|}{$\mathbf{R V}$} \\
\hline & & & Litres & $\begin{array}{c}\% \\
\text { Pred. }\end{array}$ & $\underset{\mathrm{mmHg}}{\mathrm{ml} / \mathrm{min} /}$ & $\begin{array}{c}\% \\
\text { Pred. }\end{array}$ & $\underset{\mathrm{mmHg}}{\mathrm{ml} / \mathrm{min} /}$ & $\begin{array}{c}\% \\
\text { Pred. }\end{array}$ & Litres & $\begin{array}{c}\% \\
\text { Pred. }\end{array}$ & Litres & $\begin{array}{c}\% \\
\text { Pred. }\end{array}$ \\
\hline $\begin{array}{l}\text { Mean } \\
\text { Range } \\
\text { SEM }\end{array}$ & $\begin{array}{c}172 \cdot 1 \\
150-187 \\
1.87^{1}\end{array}$ & $\begin{array}{c}35 \cdot 2 \\
13-68 \\
2 \cdot 259\end{array}$ & $\begin{array}{c}2 \cdot 5 \\
1.51-4.05 \\
0.164\end{array}$ & $\begin{array}{c}71 \\
31-104 \\
3.83\end{array}$ & $\begin{array}{c}30 \cdot 5 \\
17 \cdot 1-47 \cdot 0 \\
1.51\end{array}$ & $\begin{array}{c}97 \cdot 5 \\
63-124 \\
3 \cdot 12\end{array}$ & $\begin{array}{c}28 \cdot 4 \\
18-43 \cdot 5 \\
1 \cdot 34\end{array}$ & $\begin{array}{c}91.4 \\
60-128 \\
2.91\end{array}$ & $\begin{array}{c}6 \cdot 28 \\
4 \cdot 02-9 \cdot 12 \\
0 \cdot 266\end{array}$ & $\begin{array}{c}101 \\
68-128 \\
2 \cdot 56\end{array}$ & $\begin{array}{c}2 \cdot 32 \\
0 \cdot 71-4 \cdot 40 \\
0 \cdot 17\end{array}$ & $\begin{array}{c}127 \\
47-210 \\
7.68\end{array}$ \\
\hline
\end{tabular}

The standard error of the mean for height for the males and females can be expressed separately because of the large difference in the mean values. SEM:-males $1 \cdot 584$, females $1 \cdot 831$. 
T A B L E I I I

TL AND TL' IN ASTHMATIC AND NORMAL SUBJECTS (numbers of subjects exceeding the predicted value by 1 or 2 SD)

\begin{tabular}{|c|c|c|c|c|}
\hline & \multicolumn{2}{|c|}{$\begin{array}{l}\text { Asthmatic } \\
\text { Subjects }\end{array}$} & \multicolumn{2}{|c|}{$\begin{array}{l}\text { Normal } \\
\text { Subjects }\end{array}$} \\
\hline & $T^{\prime} \mathbf{L}^{\prime}$ & $T_{L}$ & $\mathbf{T L}^{\prime}$ & TL \\
\hline $\begin{array}{l}2 \text { SD over } \\
\text { predicted } \\
1 \text { SD over } \\
\text { predicted }\end{array}$ & $\begin{array}{l}0 \\
1\end{array}$ & $\begin{array}{l}0 \\
6\end{array}$ & $\begin{array}{l}1 \\
4\end{array}$ & $\begin{array}{l}0 \\
2\end{array}$ \\
\hline
\end{tabular}

normal subjects whose $T_{\mathbf{L}}$ or $\mathbf{T}_{\mathbf{L}}{ }^{\prime}$ exceeded the predicted value by more than 1 or $2 \mathrm{SD}$. There were no significant differences between the asthmatic and normal groups in height, age or total lung capacity.

The same inspired volume was used for calculations of $T_{L}$ and $T_{L^{\prime}}$. The difference between $V_{A}$ and $V_{A^{\prime}}$ depends on the method of helium dilution used. $V_{\mathbf{A}^{\prime}}$ is estimated from a residual volume obtained by dilution of a single breath and $V_{A}$ from a separate multiple breath estimation. When the residual volume and the difference between the $T_{L}$ and $T_{L}{ }^{\prime}$ are correlated, the value of $r$ is $\mathbf{0 . 7 5}$ for the asthmatic subjects. This relationship can be seen in Fig. 2, which shows residual volume plotted against $T_{L}$ and $T_{L}{ }^{\prime}$ in the asthmatic subjects who had a moderate degree of airways obstruction as shown by an $\mathrm{FEV}_{1}$ less than $70 \%$ of predicted. The values are expressed as per cent of predicted to show the subjects with a high residual volume more clearly. It is seen that the subjects with a high residual volume had a larger difference between $T_{L}$ and $T_{L}{ }^{\prime}$ than those with a low or normal residual volume. The lowest residual volume shown was 1.01 litres and the difference between $T_{L}$ and $T_{L}{ }^{\prime}$ was
$1.4 \mathrm{ml} / \mathrm{min}$ per $\mathrm{mmHg}$, while the largest residual volume was 4.4 litres with a difference of $11.2 \mathrm{ml} / \mathrm{min}$ per $\mathrm{mmHg}$, between the methods.

There was a poor correlation between the $\mathrm{FEV}_{1}$ and the difference between $T_{L}$ and $T_{L}{ }^{\prime}(r=0.35)$ and Fig. 3

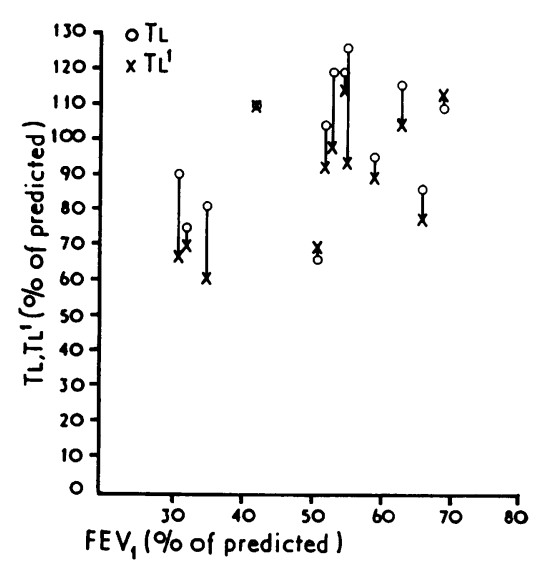

FIG. 3. $\mathrm{T}_{\mathrm{L}}, \mathrm{T}_{\mathrm{L}}^{\prime}$, and $\mathrm{FEV}_{1}$ in patients with $\mathrm{FEV}_{1}$ less than $70 \%$ of predicted.

shows this for the subjects with $\mathrm{FEV}_{1}$ less than $70 \% \stackrel{\mathbb{\perp}}{\varrho}$ of predicted. There were four subjects with $\mathbf{T}_{\mathbf{L}}{ }^{\prime}$ below $\overrightarrow{\bar{O}}$ $70 \%$ of predicted, of whom two were 2 SD below 3 predicted for $\mathrm{T}_{\mathbf{L}}{ }^{\prime}$. One subject had $\mathrm{T}_{\mathrm{L}}$ below $70 \%$ of predicted and 2 SD below predicted. It is most striking that nearly all those subjects with moderate airways obstruction had a normal $T_{L}$ and $T_{L^{\prime}}$. There was also a poor correlation between $F E V_{1}$ and $T_{L}{ }^{\prime}$ $(r=0 \cdot 29)$.

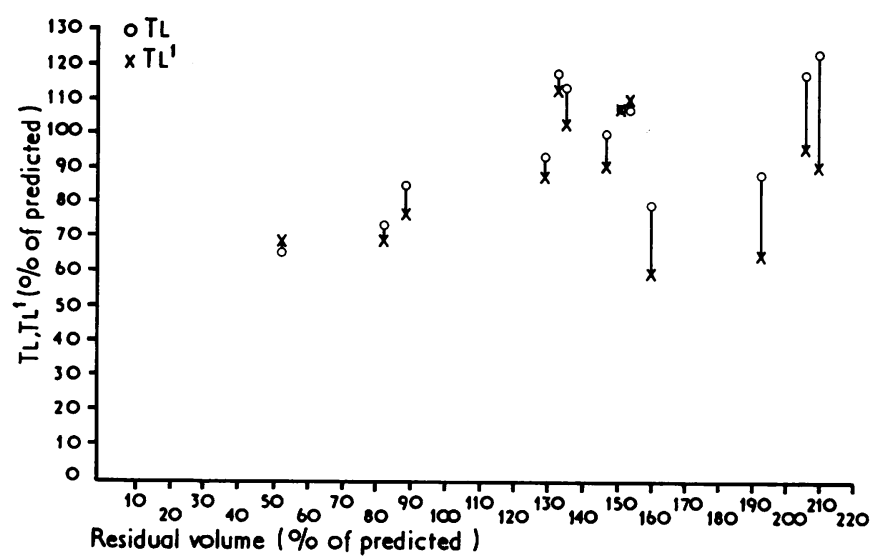

FIG. 2. $\mathrm{T}_{\mathbf{L}}, \mathrm{T}_{\mathbf{L}}{ }^{\prime}$, and residual volume in 13 asthmatic subjects with FEV $_{1} 0$ less than $70 \%$ of predicted. 


\section{DISCUSSION}

There are conflicting reports that the single breath transfer factor is normal, high or low in asthma. There are several possible reasons for this apparent difference. First, it could be due to the different methods used to measure residual volume and hence alveolar volume. Second, there could be real differences arising from the varying degree of severity of the airways obstruction. Cotes et al. (1970) reported a group of female asthmatic subjects with a mean $F E_{1}$ of $2 \cdot 1$ litres and failed to find a high transfer factor whereas the group of males and females described by Evans and Ogilvie (1970) had a mean $F^{2} V_{1}$ of 1.8 litres and there were a number with a high transfer factor. The present study is an attempt to see if the different residual volume calculation is a possible explanation and indeed it seemed to be so. For the study a group of relatively mild asthmatics in remission were deliberately chosen. The mean value of $\mathrm{FEV}_{1}$ was 2.5 litres. A group of normal subjects who were closely comparable with regard to age, height, sex distribution, total lung capacity, and smoking habits were studied concurrently. As Cotes et al. (1970) pointed out, the higher the alveolar volume estimation, the higher will be the transfer factor because the alveolar volume is used directly in the calculation. Mitchell and Renzetti (1968) reported that the single breath method gave higher values for alveolar volume than the multiple breath method in normal subjects and in a group of subjects with various forms of obstructive airways disease. However, Teculescu and Stanescu (1969) found that in asthmatic subjects the single breath method gave a lower value for the alveolar volume.

In the study reported here, $T_{L}$ was higher than $T_{L}{ }^{\prime}$ in the asthmatic subjects while $T_{L}{ }^{\prime}$ was higher than $T_{L}$ in the normal subjects. The only difference in the calculation was the value of alveolar volume. It follows that the alveolar volume was higher by the multiple breath method in the asthmatic subjects, while it was higher by the single breath method in the normal subjects. The reports of a raised transfer factor in asthma were from workers who used $T_{L}$ (multiple breath alveolar volume) and they would therefore probably get higher values for transfer factor than if $T_{L}{ }^{\prime}$ were used. These findings could explain why a raised transfer factor was not found by workers using the single breath alveolar volume. Although in this study none of the asthmatic subjects had a transfer factor more than 2 SD above predicted, Table III shows that six had a TL 1 SD above predicted. In addition, it has been shown that the difference between $T_{L}$ and $T_{L}{ }^{\prime}$ was greater in those with a high residual volume. It seems that the single breath method for alveolar volume underestimates most seriously when the residual volume is high. This would be expected as gas mixing would be less efficient and the degree of helium dilution less in these circumstances.

The finding by Evans and Ogilvie (1970) of a high single breath transfer factor in asthma is supported by other reports. Pecora, Bernstein, and Feldman (1966) reported a high single breath transfer factor $\left(T_{L}\right)$ and high membrane component of diffusion (D $\mathrm{M}$ ) in asthmatic children with permanently raised functional residual capacity and recently Ohman $e t$ al. (1973) found a high $T_{L}$ and $D_{M}$ in some adults with asthma. The raised $\mathrm{D}_{M}$ cannot be accounted for by the calculation of the residual volume and would provide a mechanism for the increased transfer factor. There are theoretical reasons for the rise in $D_{M}$ such as increased surface area and thinning of the alveolar membrane, though the relative importance of these factors is not clear. A third explanation for the increased transfer factor would be an increase in pulmonary inflation in more severe airways obstruction with recruitment of closed alveoli and increase in alveolar volume. Also in cases with significant hypoxia there could be increased uptake of carbon monoxide by haemoglobin. An increased $D_{M}$ should be reflected in an increased transfer coefficient (KCo). In this particular study there was no significant difference in Kco between the normal $(5 \cdot 12 \pm 0 \cdot 227)$ and asthmatic $(5 \cdot 57 \pm 0 \cdot 204)$ subjects, although the mean value was rather higher in the latter. The reason for this may be that the patients in this study had less severe airways obstruction and fewer had a permanent increase in residual volume and functional residual capacity than was found by the authors reporting high $D_{M}$ and $T_{L}$. It is not clear why the normal subjects had a $\operatorname{larger} T_{L^{\prime}}{ }^{\prime}$ and $V_{A}{ }^{\prime}$. This must arise from a greater degree of helium dilution in the single breath method, either $(a)$ increased numbers of alveoli being fully ventilated with helium because there is a period of several seconds' breathholding at total lung capacity while the rebreathing method is performed at nearer to tidal levels, or $(b)$ increased numbers of alveoli being opened up by the greater inspiratory effort of the single breath test.

There are reports that transfer factor is low when airways obstruction becomes more pronounced (Palmer and Diament, 1969b). As can be seen in Fig. 3, only four of the 13 asthmatic subjects with FEV 1 less than $70 \%$ of predicted had $T_{L^{\prime}}{ }^{\prime}$ less than $70 \%$ of predicted, and only two of these had values more than 2 SD below predicted. The results for $T_{L}$ are mostly higher, and only one subject had a value of 2 SD below predicted and below $70 \%$ of the predicted value. The finding of a low transfer factor 
in asthma, even when the $F E V_{1}$ is moderately reduced, was uncommon in this series; nor $\operatorname{did} T_{L}$ and $T_{L}{ }^{\prime}$ differ between the groups of asthmatic and normal subjects.

The value of the single breath transfer factor in chronic airways obstruction needs careful evaluation. Though it is frequently reduced in emphysema, it is commonly normal in asthma. The finding of a low transfer factor is, therefore, against the diagnosis of asthma. Even when airways obstruction is quite severe the transfer factor is usually relatively well preserved. However, the present study indicates that the actual value obtained for transfer factor can vary according to the method used for measuring residual volume and therefore the alveolar volume.

I wish to thank Dr. David Hughes for help with the preparation of this paper, and Mrs. Carole Bye for the statistical analysis.

\section{REFERENCES}

Cotes, J. E. (1968). Lung Function, 2nd ed. Blackwell, Oxford.

, Dabbs, J. M., McDonald, A., Davies, S. E., and Hall, A. M. (1970). Transfer factor in asthma. Lancet, 1, 626.

Evans, C. C. and Ogilvie, C. M. (1970). Transfer factor in asthma. Lancet, $1,891$.

Fletcher, C. M., Hugh-Jones, P., McNicol, M. W., and Pride, N. B. (1963). The diagnosis of pulmonary emphysema in the presence of chronic bronchitis. Quarterly Journal of Medicine (New Series), 32, 33.

McGrath, M. W. and Thomson, M. L. (1959). The effect of age, body size and lung volume change on alveolarcapillary permeability and diffusing capacity in man. Journal of Physiology, 146, 572.
Meisner, P. and Hugh-Jones, P. (1968). Pulmonary function in bronchial asthma. British Medical Journal, $1, \stackrel{\square}{\square}$ 470.

Mitchell, M. M. and Renzetti, A. D. (1968). Evaluation of a single-breath method of measuring total lung $\vec{\Phi}$ capacity. American Review of Respiratory Disease, 97, 571.

Ogilvie, C. M. (1968). Pulmonary function in asthma. $\overrightarrow{0}$ British Medical Journal, 1, 768.

, Forster, R. E., Blakemore, W. S., and Morton, J. W. $\vec{\omega}$ (1957). A standardised breath holding technique for the clinical measurement of the diffusing capacity of the lung for carbon monoxide. Journal of Clinical $x$ Investigation, 36, 1.

Ohman, J. L. Jr., Schmidt-Nowara, W., Lawrence, M., iv Kazemi, H., and Lowell, F. C. (1973). The diffusing in capacity in asthma. Effect of airflow obstruction. N American Review of Respiratory Disease, 107, 932.

Palmer, K. N. V. and Diament, M. L. (1969a). Dynamic and static lung volumes, blood-gas tensions, and transfer factor in chronic obstructive bronchitis. Lancet, 1, 1073. and - (1969b). Dynamic and static lung volumes and blood-gas tensions in bronchial asthma. $\vec{\theta}$ Lancet, 1, 591.

Pecora, L. J., Bernstein, I. L., and Feldman, D. P. (1966) Pulmonary diffusing capacity, membrane diffusing capacity, and capillary blood volume in children with intractable asthma with and without chronic overinflation of the lungs. Journal of Allergy, 37, 204.

Teculescu, D. B. and Stanescu, D. C. (1969). Total lung capacity in obstructive lung disease. Comparative $\Omega$ determinations by single and multiple breath helium $\overline{\bar{O}}$ dilution. Bulletin de Physio-pathologie Respiratoire, 5, 453 .

Requests for reprints to: Dr. S. P. Haydu, Lung Function Laboratory, The London Hospital, Whitechapel, London E1 1BB. 